\title{
Fetal chondrodysplasia punctata associated with maternal autoimmune diseases: a review
}

This article was published in the following Dove Press journal:

The Application of Clinical Genetics

\section{Hadeel Alrukban' \\ David Chitayat ${ }^{1,2}$}

'Department of Pediatrics, Division of Clinical and Metabolic Genetics, the Hospital for Sick Children, University of Toronto, Toronto, ON, Canada; ${ }^{2}$ Department of Obstetrics and Gynecology, The Prenatal Diagnosis and Medical Genetics Program, University of Toronto, Toronto, ON, Canada
Correspondence: David Chitayat Department of Obstetrics and Gynecology, The Ontario Power Generation Building, 700 University Avenue, Room 3-709, M5G IZ5,

Toronto, ON, Canada

$\mathrm{Tel}+\mathrm{I} 4 \mathrm{I} 65864523$

Fax + I 4165864723

Email dchitayat@mtsinai.on.ca

\begin{abstract}
Chondrodysplasia punctata (CDP) is a skeletal abnormality characterized by premature calcification that is usually noticeable in the prenatal period and infancy. Etiologically, the condition is heterogeneous, and the causes include fetal conditions such as chromosome abnormalities, peroxisomal disorders, lysosomal storage disorders, cholesterol synthesis defects and abnormal vitamin $\mathrm{K}$ metabolism, as well as maternal diseases such as severe malabsorption and exposure to teratogens. An association between CDP and maternal autoimmune disease was first observed and reported by Curry et al and Costa et al in 1993 and expanded by Chitayat et al in 2010. This review lists the clinical characteristics and radiologic findings of all cases reported to date in English and discuss the possible etiology of this interesting fetal finding.

Keywords: stippled epiphyses, peroxisomal disorders, vitamin K, chromosome abnormalities, intrauterine growth restriction epiphysis, growth plate
\end{abstract}

\section{Introduction}

Chondrodysplasia punctata (CDP) is a skeletal abnormality characterized by premature foci of calcification, referred to as stippling, within the cartilage. It is most commonly found in the epiphysis of the long bone, vertebral column and other cartilaginous regions that do not normally calcify, including the trachea and the rib ends. These foci of calcifications can be visualized radiologically by fetal ultrasound and X-rays during the newborn and infancy periods. As the cartilage starts to calcify, these foci are no longer visible, and this diagnosis can be missed and can become challenging.

$\mathrm{CDP}$ is etiologically heterogeneous. Irving et $\mathrm{al}^{1}$ divided the etiologies into four groups as follows: inborn error of metabolism, disruption of vitamin $\mathrm{K}$ metabolism, chromosomal abnormalities and a fourth group that includes maternal factors and a number of unclassified etiologies.

The inborn errors of metabolism associated with CDP include peroxisomal disorders, type 2 mucolipidosis, type 3 mucopolysaccharidosis and GM1 gangliosidosis. Peroxisomes are membrane-bound organelles found within almost all eukaryotic cells. Contained within the peroxisome matrix of mammalian cells are over 70 distinct enzymes required for normal lipid metabolism and a host of other biochemical processes critical for normal health and development. ${ }^{2}$ Defects in peroxisome formation result in dysfunction of a group of metabolic diseases collectively known as peroxisome biogenesis disorders. This group of disorders is divided into two subtypes: Zellweger spectrum disorder and rhizomelic CDP (RCDP) type 1. The second group of peroxisomal disorders involves single enzyme defects. Other peroxisomal disorders associated with RCDP are RCPD 
type 2 and 3. CPD type 2 is caused by deficiency of the peroxisomal enzyme dihydroxyacetone phosphate acyltransferase, encoded by GNPAT (OMIM 602744). RCDP3 is caused by deficiency of the peroxisomal enzyme alkyl-dihydroxyacetone phosphate synthase, encoded by AGPS (OMIM 600121). Zellweger spectrum disorder and rhizomelic CDP types 1-3 share similar punctate cartilaginous changes. ${ }^{3}$

Abnormality of cholesterol metabolism is another cause of CDP. Defects in this pathway result in multisystem anomalies, attributable to the fact that cholesterol is an essential and ubiquitous chemical with an integral role in many developmental pathways and cell membranes. Cholesterol biosynthesis is a complex pathway that can be divided into two main parts. The so-called pre-squalene part leads to the biosynthesis of both isoprenoids (including the intermediate precursor named squalene) and sterols; the post-squalene metabolic steps are committed to the synthesis of cholesterol and vitamin D. ${ }^{4,5}$ Ten disorders of the post-squalene pathway have been recognized, leading to a variable combination of intellectual disability and malformations with significant skeletal involvement. Smith-Lemli-Opitz syndrome (OMIM 270400), Conradi-Hünermann syndrome (OMIM 302960), Greenberg dysplasia (OMIM 125140) and congenital hemidysplasia with ichthyosiform erythroderma and limb defects, more commonly known by the acronym CHILD syndrome (OMIM 308050), are examples of this group of diseases. ${ }^{5}$

CDP is also seen in association with chromosomal abnormalities such as Turner syndrome, Down syndrome, trisomy 18 (Edwards's syndrome) and trisomy $9^{6,7}$ and with maternal exposure to cytomegalovirus or rubella viruses.

Fetal exposure to warfarin, an anticoagulant that is a commonly used for the prevention and treatment of thrombosis, carries the risk of developing warfarin embryopathy. The condition is primarily characterized by nasal bone hypoplasia and skeletal abnormalities, including short limbs and digits (brachydactyly), and stippled epiphyses. ${ }^{8}$ Warfarin functions by inhibiting vitamin $\mathrm{K}$ epoxide reductase complex 1, an essential enzyme through which vitamin $\mathrm{K}$ is recycled, leading to deficiency of vitamin $\mathrm{K}$ and as a result reduction in the function of vitamin K-dependent enzymes. ${ }^{9}$ Vitamin $\mathrm{K}$ acts as a coenzyme for a carboxylase that functions to activate several coagulation factors, coagulation inhibitors and other proteins such as osteocalcin, matrix-Gla protein and periostin. The latter three proteins are involved in the mineralization process of bones and teeth. Deficiency of vitamin K leads to undercarboxylation of Gla proteins, which, in turn, leads to abnormal calcium deposition and aberrant growth of cartilage. ${ }^{10-12}$

Another enzyme that is dependent on vitamin $\mathrm{K}$ is arylsulfatase $\mathrm{E}(A R S E)$, a member of the sulfatases group that is essential for bone and cartilage development. Deficiency of this enzyme results in X-linked recessive CDP. ${ }^{13}$

The association of CDP and maternal autoimmune diseases, namely, systemic lupus erythematosus (SLE), was first presented by Curry et al at the David Smith meeting in $1993^{14}$ and by Costa et al (1993), at the first meeting of the International Skeletal Dysplasia Society. ${ }^{15}$ Subsequently, 29 cases were reported, in association not only with SLE but also with mixed connective tissue disease (MCTD) and Sjögren syndrome. This article reviews the clinical, radiologic and biochemical characteristics of all reported cases with CDP born to mothers with autoimmune diseases.

\section{CDP and SLE}

SLE is a chronic autoimmune disease that affects various body systems. Patients present with variable clinical features ranging from mild joint and skin involvement to life-threatening renal, hematologic or central nervous system involvement. A revised diagnostic criterion has been proposed by the SLE International Collaborating Clinics in 2012. ${ }^{16}$ This criterion requires that a patient either satisfy at least 4 of 17 criteria, including at least 1 of the 11 clinical criteria and 1 of the 6 immunologic criteria, or that the patient has biopsy-proven nephritis compatible with SLE in the presence of antinuclear antibodies (ANAs) or anti-double-stranded DNA antibodies.

ANAs are antibodies that target normal proteins within the nucleus of the cell. The presence of these antibodies in abundance indicates an autoimmune disease. There are many subtypes of ANAs, such as anti-Ro antibodies, antiLa antibodies, anti-Sm antibodies, anti-nRNP antibodies and anti-double-stranded DNA antibodies. Each of these subtypes of antibody binds to different proteins or protein complexes within the nucleus. Pregnancies in women affected with SLE carry a higher maternal and fetal risk. About $1 \%-2 \%$ of babies born to women with SLE develop neonatal lupus. ${ }^{17}$ Following the report of McCuistion et al showing that SLE-like skin changes are found in newborns to mothers with SLE, ${ }^{18}$ it was recognized that fetuses/neonates can have manifestations associated with maternal SLE. Neonatal lupus is a disease caused by passively transferred maternal autoantibodies leading to immunologic injury with most manifestations in the newborn being transient. These babies display cutaneous, hematologic, liver and cardiac manifestations. Skeletal manifestations include epiphyseal stippling, distal phalangeal hypoplasia and midface hypoplasia with hypoplastic nasal bone. We reviewed all cases of neonates with CPD born to mothers with SLE reported to date ${ }^{15,19-27}$ and have summarized their antenatal history, clinical and radiologic findings in Table 1 . 


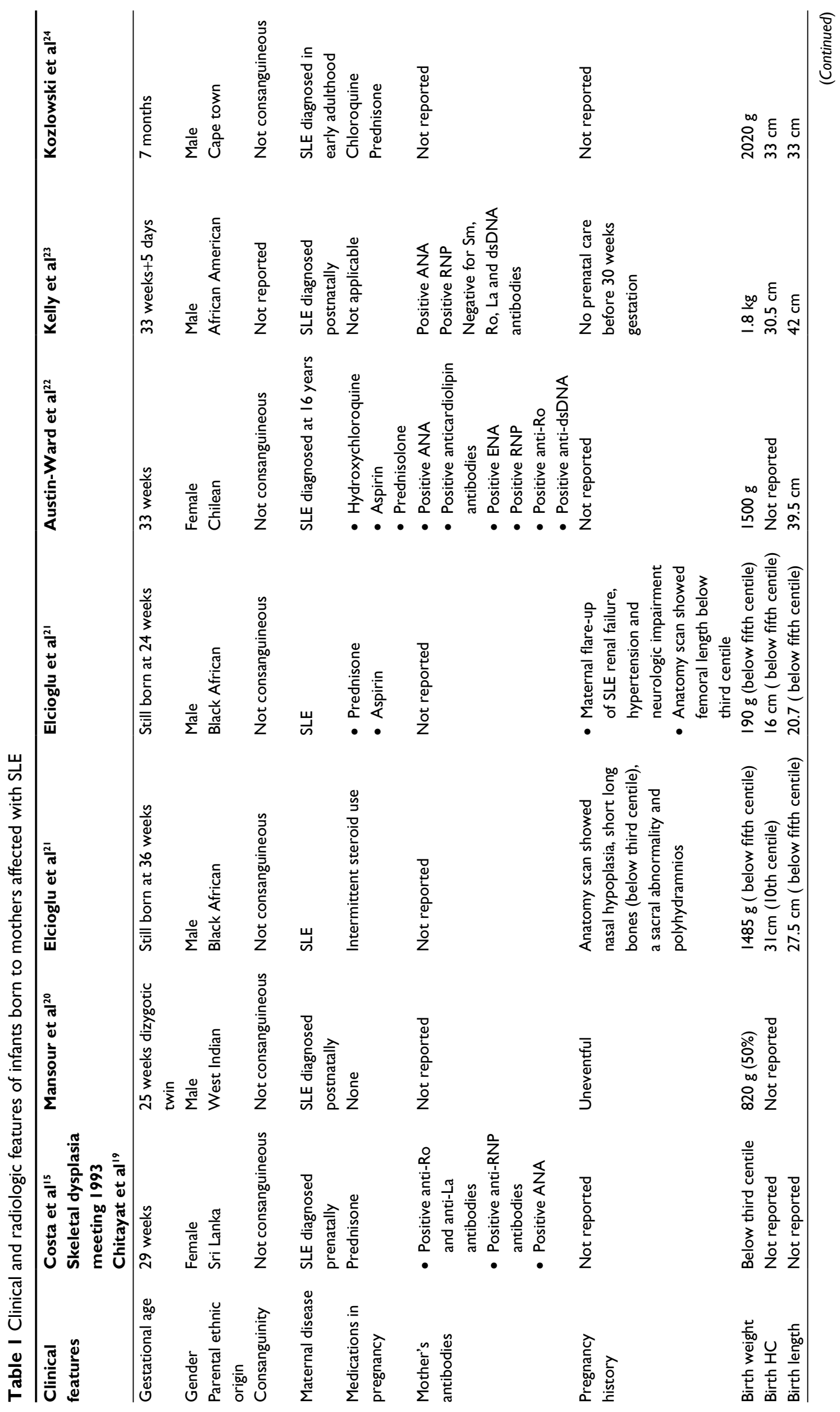




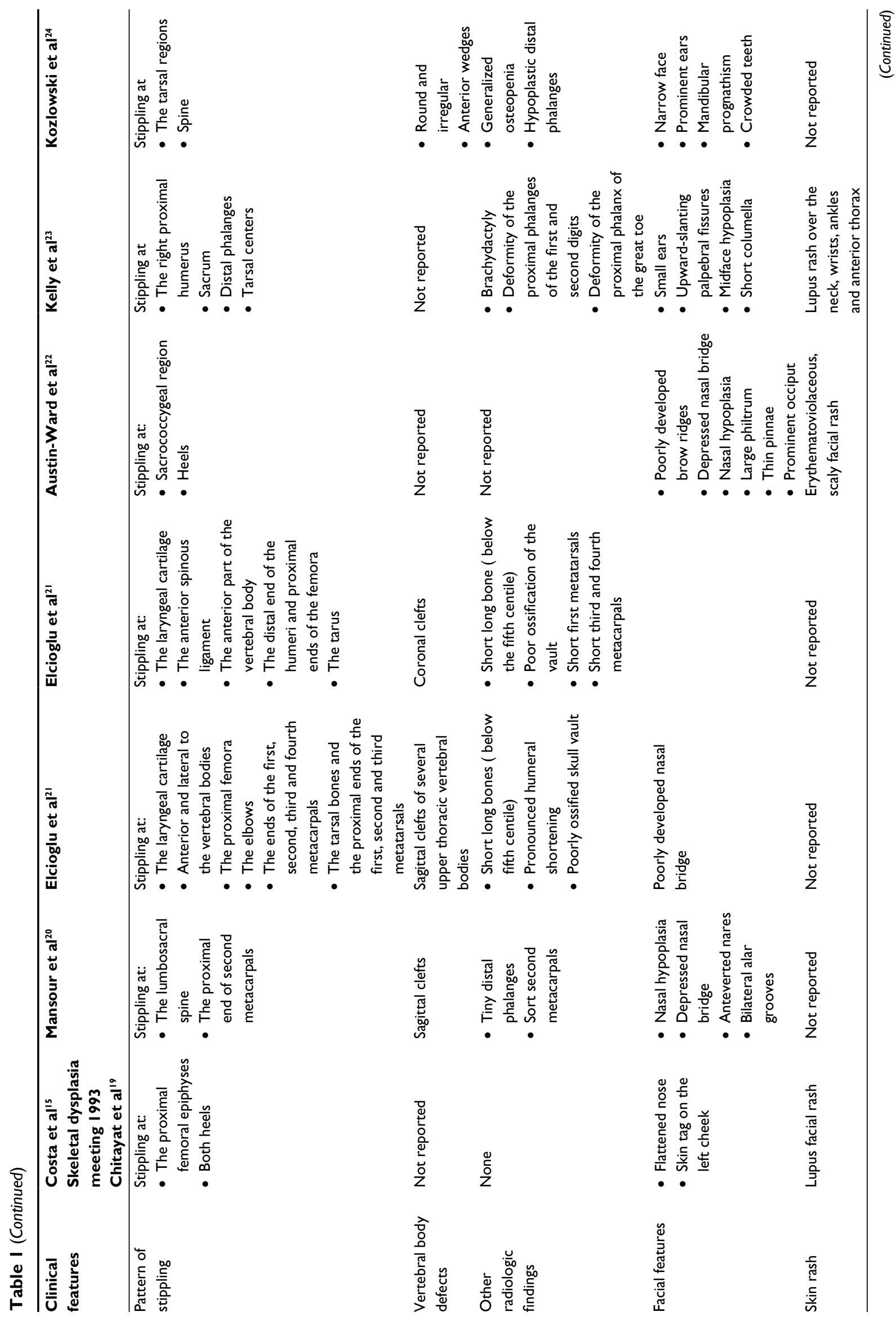




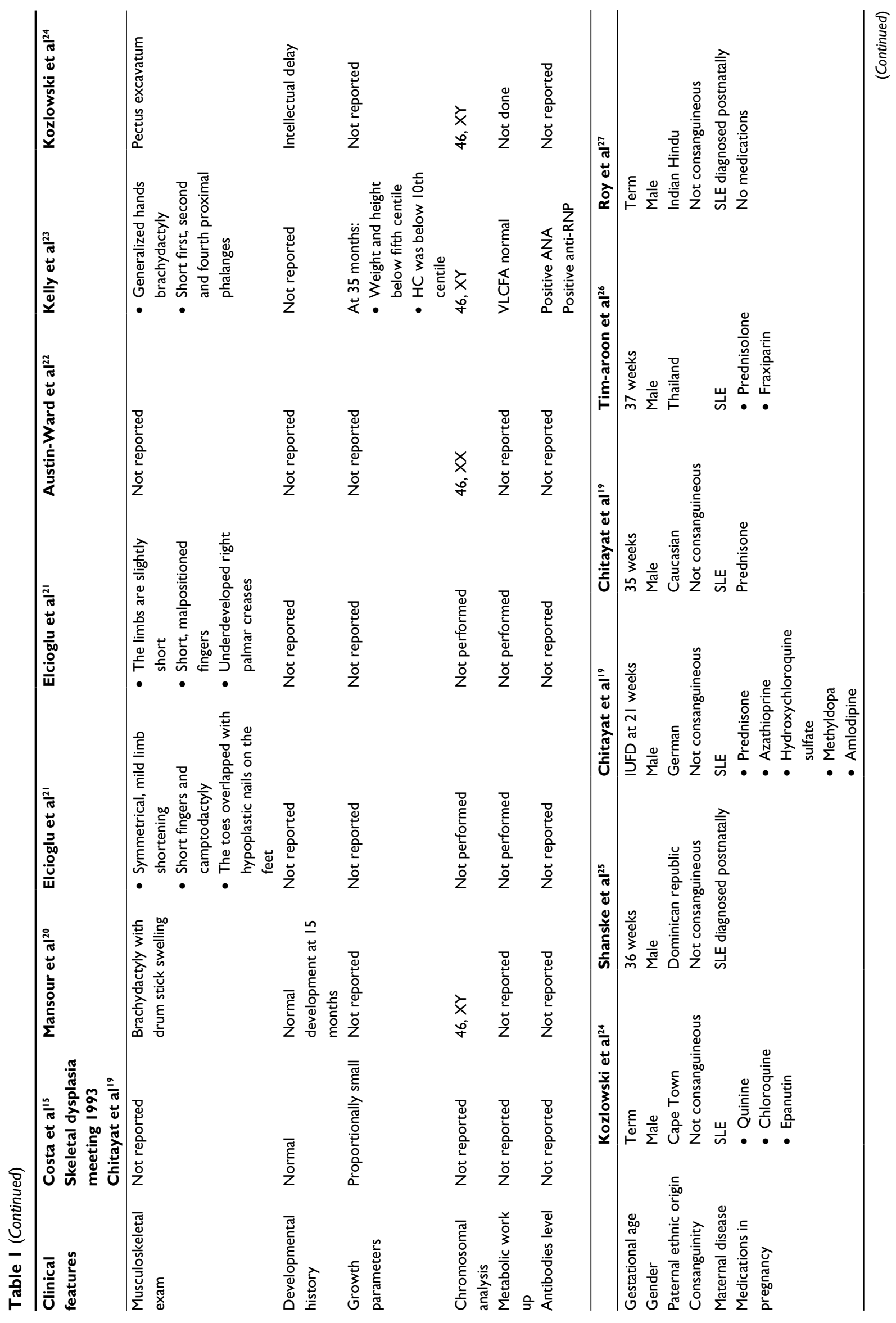




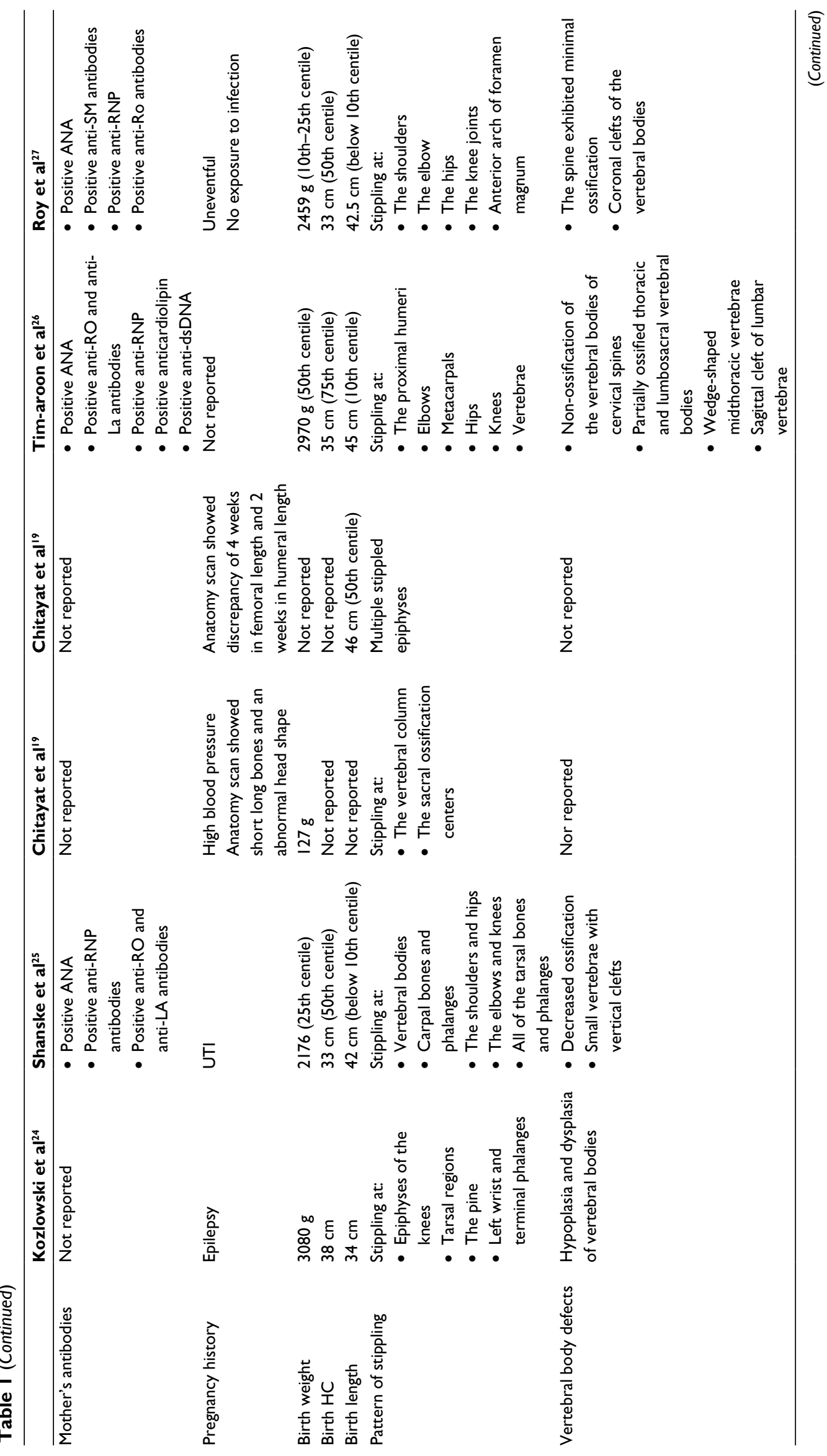




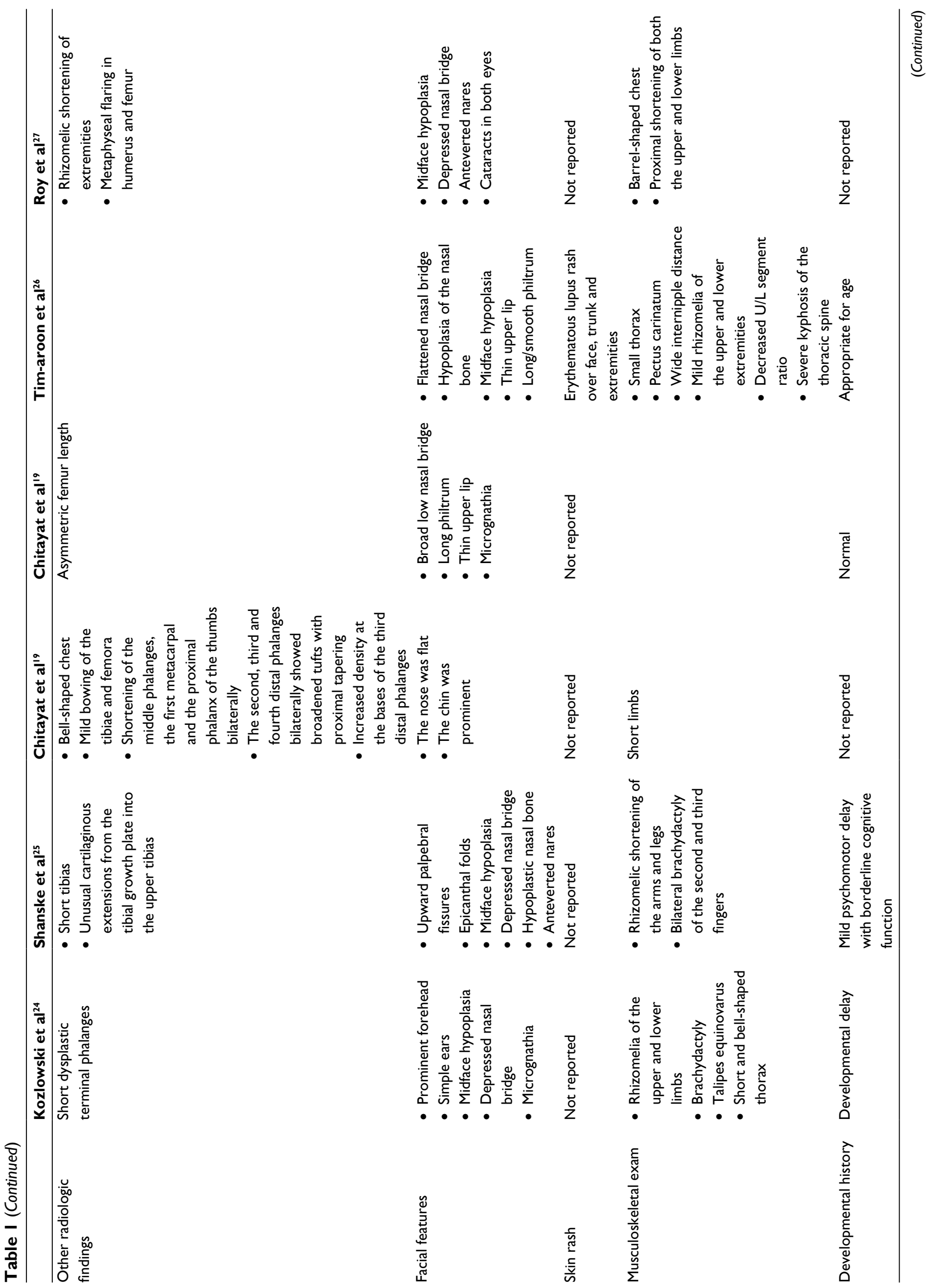




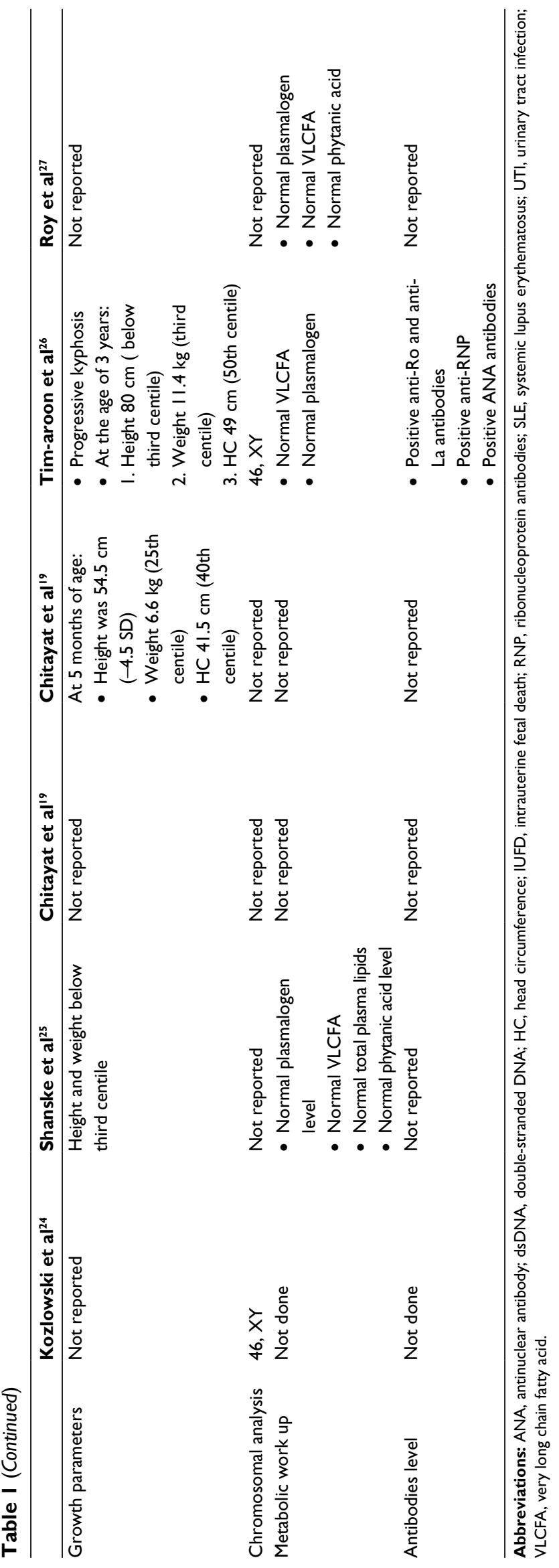

\section{CDP and MCTD}

The concept of MCTD as a separate immune-mediated connective tissue disease was first introduced by Sharp et al $>40$ years ago, ${ }^{28}$ but there is still no consensus regarding the disease definitions, classification, criteria or the relationship with other autoimmune conditions. ${ }^{28,29}$ Different set of diagnostic criteria were proposed. MCTD may begin with any clinical manifestation associated with SLE, systemic sclerosis, polymyositis or rheumatoid arthritis at the initial presentation or during the clinical course. The most common clinical features are polyarthritis, Raynaud's phenomenon, sclerodactyly, swollen hands, muscle disorders and esophageal dysmotility. The anti-U1-RNP antibodies are the hallmark of the disease. Patients with high titers without any criteria of MCTD or other defined connective tissue disease usually evolve into MCTD in about 2 years. ${ }^{29}$ Seven affected women who gave birth to neonates with CDP have been reported to date. Table 2 lists the clinical, radiologic and biochemical manifestations of these cases. . $^{14,15,19,30}$

\section{Sjögren syndrome and CDP}

Sjögren syndrome is a chronic disease in which the body's immune system abnormally attacks secretory glands. The clinical presentation can extend to systemic involvement (extraglandular manifestations). Martin et $\mathrm{al}^{31}$ reported the first and the only case of a child with CPD born to a mother with Sjögren syndrome. The mother was diagnosed with the syndrome at the age of 21 and got pregnant at the age of 36 . At that time, she was on prednisone and hydroxychloroquine that were discontinued after her pregnancy was confirmed at 4 weeks' gestation. Fetal scan at 20 weeks' gestation showed sacral hypoplasia suggestive of a possible caudal regression syndrome. A female infant was delivered at 40 weeks with a birth weight of $2210 \mathrm{~g}$ and a length of $43 \mathrm{~cm}$ (both below first centile) and the head circumference was $33.5 \mathrm{~cm}$ (34th centile). She had large anterior fontanelle, sparse hair, marked nasal hypoplasia, wide mouth and short neck. The limbs were short with brachydactyly. She had deviated the second to fourth fingers and short middle and distal phalanges. The skeletal survey showed stippling of the carpal bones, tarsal bones, many vertebral bodies and the hyoid bone. The distal and middle phalanges on both hands were markedly hypoplastic, and the first metacarpal bone was short. Spine magnetic resonance imaging showed anomalies involving the cervical, lumbar and sacral vertebral bodies and mild spinal stenosis at $\mathrm{C} 2-\mathrm{C} 3$. Serological investigations of the newborn showed positive anti-Ro antibodies, anti-La antibodies and ANA titers. Biochemical 
tests of peroxisome function, including plasmalogen, very long chain fatty acid and phytanic acid, were within normal limits. 7-Dehydrocholesterol and plasma cholesterol were also normal. Chromosome analysis showed a normal female karyotype (46, XX), and molecular analysis of ARSE gene failed to identify a mutation. On follow-up assessments, the child's development was within normal range.

\section{Discussion}

Maternal collagen vascular disorders can be associated with a number of fetal complications including recurrent miscarriages, intrauterine deaths, intrauterine growth restriction, prematurity and heart block which can lead to hydrops fetalis. Postnatally, these disorders can result in a transient rash, congenital heart block, hematologic cytopenias and hepatobiliary and central nervous system abnormalities. ${ }^{17,19}$

CDP is a skeletal abnormality characterized by calcification of the epiphysis of the long bones, the vertebrae and other areas such as rib ends, trachea and hyoid bone. It is associated with characteristic facial features which resemble the one seen in warfarin embryopathy and with variable degrees of long bones and phalangeal shortening. CPD is seen in various genetic diseases and in association with certain exposures. To date, a total of 21 neonates with CDP, born to women with autoimmune diseases, including SLE, MCTD and Sjögren's syndrome, have been reported. These reports support the association between maternal autoimmune disease and fetal/ newborn CDP. However, it remains a diagnosis of exclusion. Chromosome analysis, single-gene disorders, and maternal diseases and exposure should be ruled out before concluding that the etiology is maternal autoimmune disease. The differential diagnosis was outlined by Chitayat et al, ${ }^{16}$ and the diagnosis, especially in fetuses, relies on the clinical and pathologic/radiologic manifestations and should include a thorough investigation to exclude chromosomal abnormalities and one of the inherited conditions such as peroxisomal disorders, arylsulfatase A and Smith-Lemli-Opitz among others, using chromosome analysis, metabolic studies, DNA analysis and, if needed, whole exome sequencing.

Observations of these cases showed that the majority (two-thirds) were males (Tables 1 and 2). Most affected neonates were born prematurely, two were still born and two died in utero. ${ }^{19,21}$ Despite diversity of ethnicity, African origin seemed predominant, which could be explained by the higher prevalence of autoimmune diseases among African-American women. ${ }^{14,19,21,23,24}$ The stippling, in these cases, did not have a specific pattern of distribution and happened anywhere across the skeleton. Vertebral abnormality is another major finding and includes reduced ossification, abnormal shapes (wedge, cone, flat and broad) and clefts. The changes in spine curvature noted in these patients are probably secondary and reflect the degree of vertebral involvement. It is difficult to comment on the final height due to lack of regular and constant follow-up of the growth parameters. Shortening of the proximal long bones was also reported in three cases $;{ }^{21,25}$ however, peroxisomal disorders were ruled out biochemically in one of the three cases only. ${ }^{25}$ Intrauterine growth restriction is another risk factor for long bone shortening. The involvement of the fingers and toes is variable in the degree of hypoplasia and the bones involved. The most common facial findings include midface hypoplasia with a poorly developed nasal bone and creases over the alae nasi and some malar flattening, similar to what is seen in fetuses exposed prenatally to warfarin. Intellectual development seems to be unaffected in these cases, although long-term follow-ups are lacking to confirm this observation. ${ }^{14,19,20,26,30}$ However, other risk factors including placental insufficiency and prematurity can increase these children's risk for developmental delay. None of the cases reported had a history of prenatal exposure to teratogens including viral infections or warfarin. Although some of the mothers received medications to treat the autoimmune condition during pregnancy, none of these medications are known to cause CDP.

The reason for the stippled epiphyses in maternal autoimmune conditions has not been delineated, and a variety of explanations have been proposed. Austin-Ward et $\mathrm{al}^{22}$ suggested that the maternal antibodies interfere with calcium-binding proteins, and Toriello ${ }^{32}$ proposed genetic susceptibility as the cause for CDP in view of the rarity and the occurrence in sibs.

We know from neonatal SLE experience that the presence of anti-Ro/SSA antibodies, with or without anti-La, rather than the type of maternal autoimmune disease, is the risk factor for the development of the disease. ${ }^{33} \mathrm{We}$ do believe that in the cases of CPD, the maternal antibodies that cross the placenta have a major role in the pathophysiology of the condition, yet the precise mechanism has not been delineated. Although not all the reported cases underwent screening for autoantibodies, the ones who did, had positive anti-RNP antibodies in common. In the mother reported by Schultz et $\mathrm{al},{ }^{30}$ serological studies failed to show the presence of anti-Ro/ $\mathrm{SSA}$ or anti-La/SSb autoantibodies and instead disclosed high titers of anti-RNP antibodies. This observation suggests that the transplacental crossing of anti-RNP or possibly another yet unidentified antibody mediate CDP. 


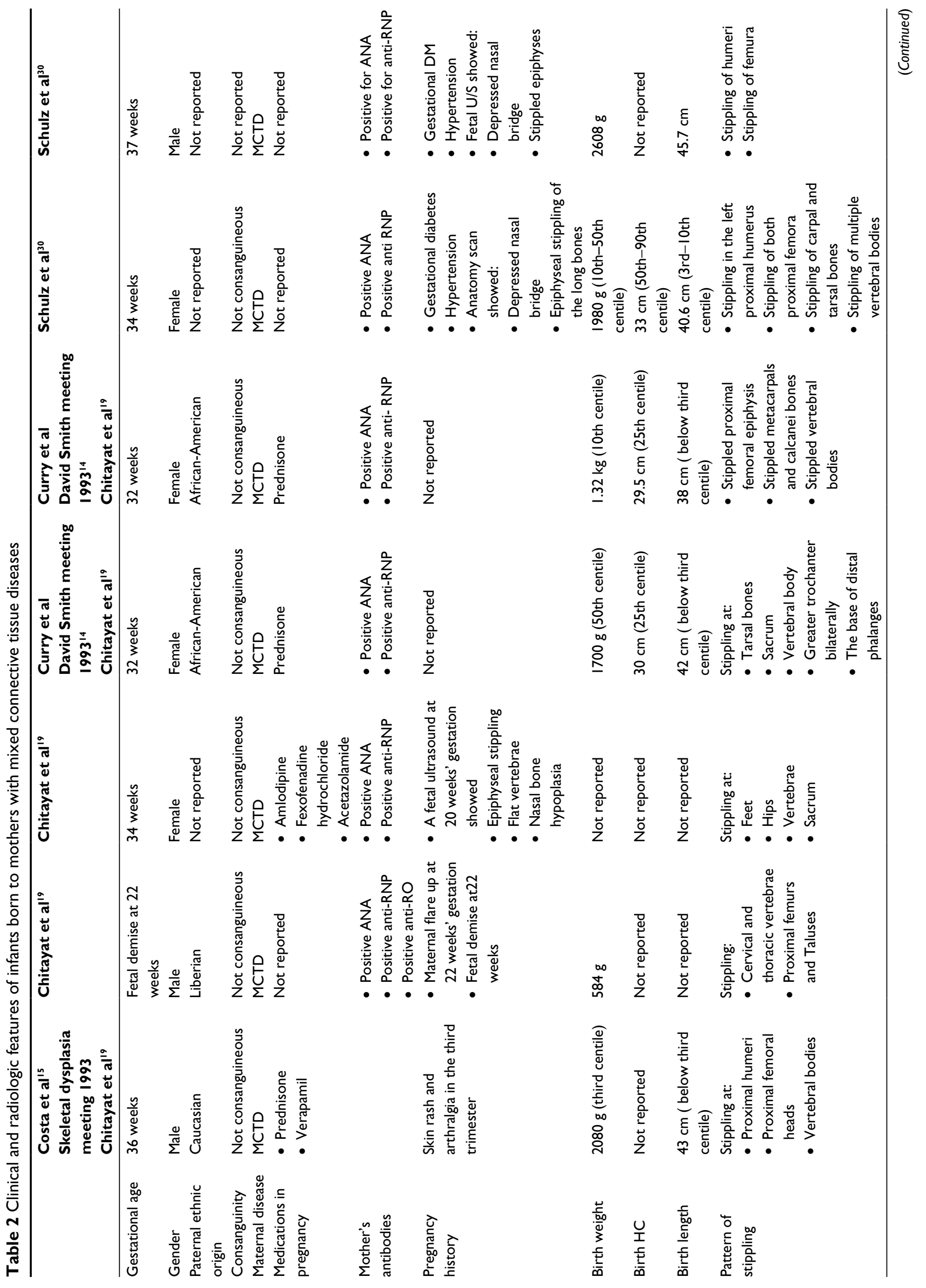




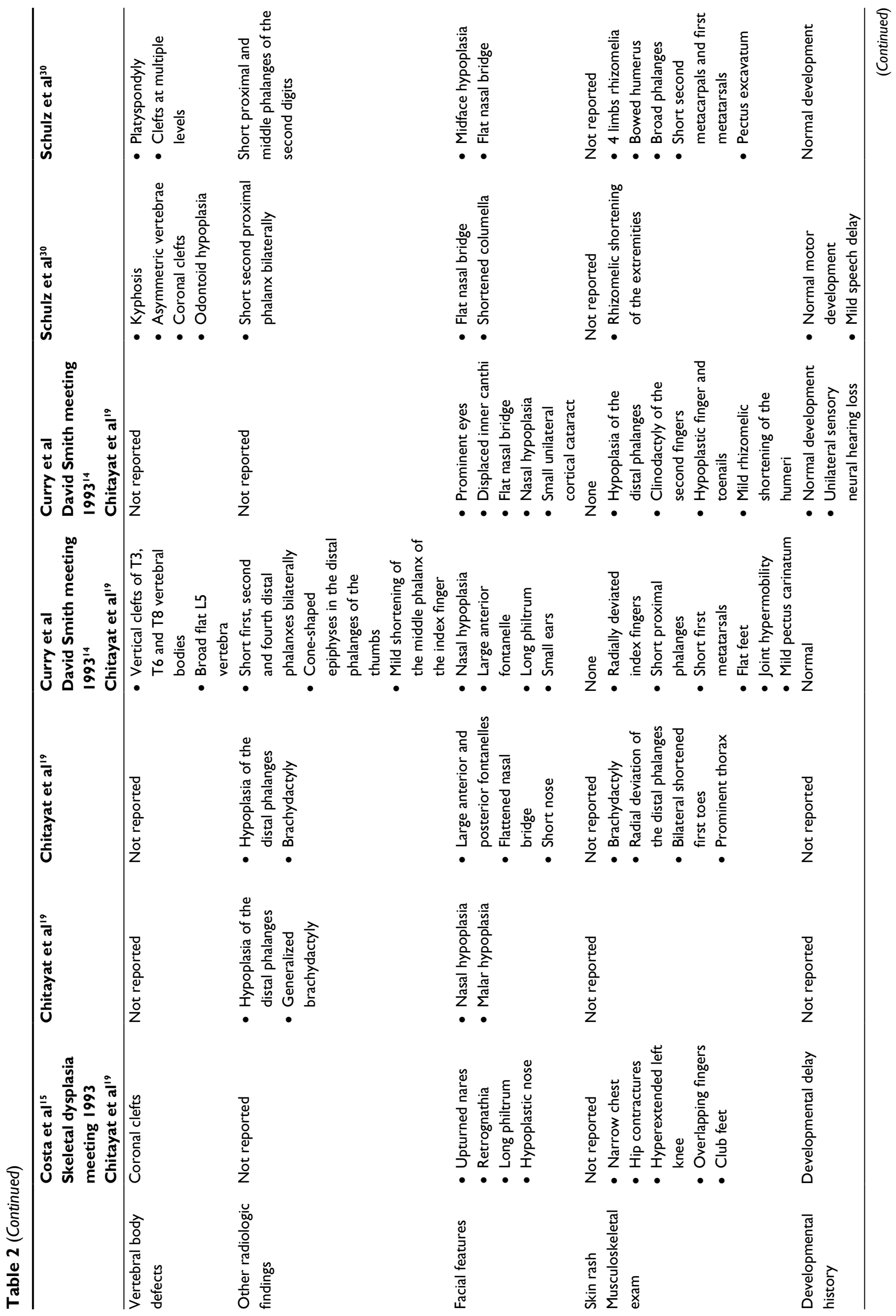




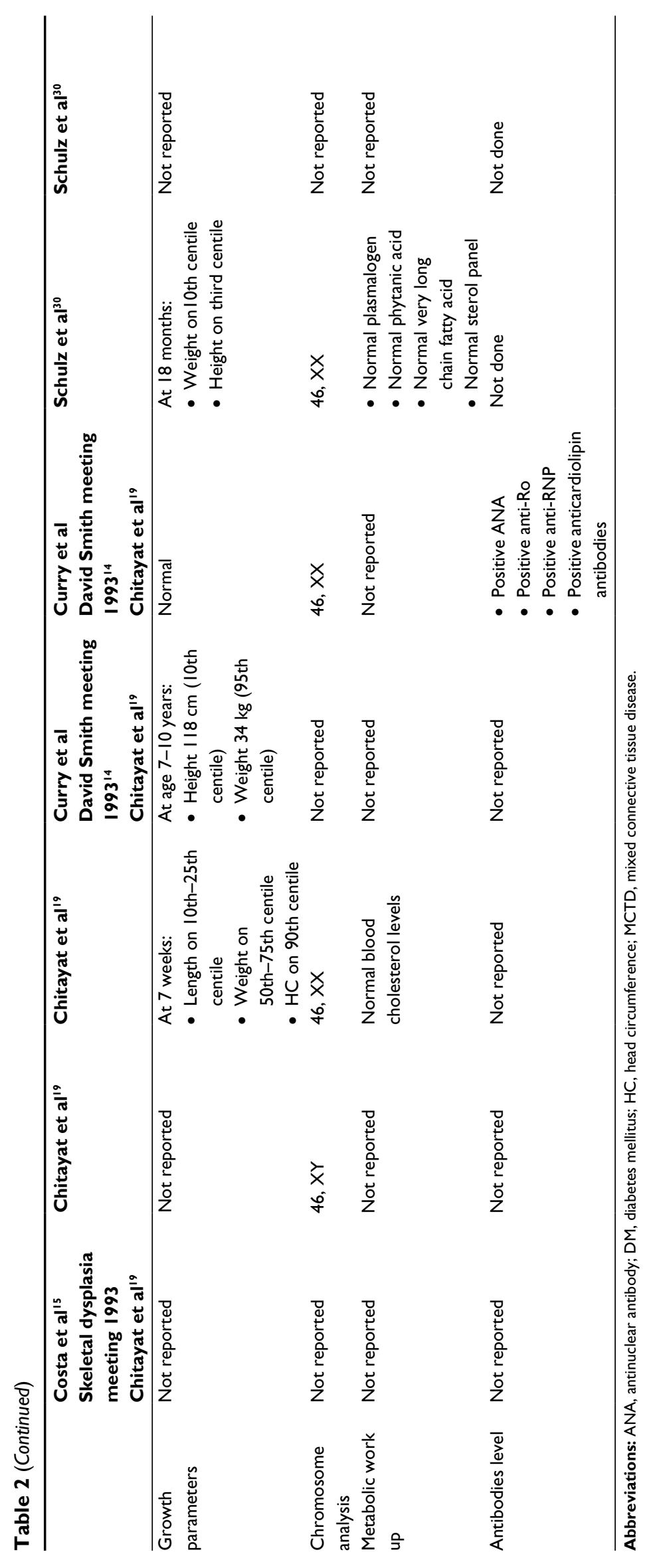


The similarity of phenotype in patients born to autoimmune disease-affected mothers with patients exposed to warfarin and patients with X-linked recessive brachytelephalangic type of CDP (CDPX1) suggests that the antibodies target proteins in the vitamin K pathway or in the pathways dependent on vitamin $\mathrm{K}$.

Vitamin $\mathrm{K}$ possesses a capacity to stimulate bone formation while simultaneously suppressing bone resorption, which is not attributable to carboxylation. Studies have demonstrated that it inhibits the synthesis of prostaglandin E2, a bone resorption-inducing agent, and it inhibits the osteoclast activity by suppressing the nuclear factor $\mathrm{\kappa B} .{ }^{10,34}$

Several reports have suggested candidate targets for the antibodies based on their role in bone morphogenesis and the knowledge gained form warfarin embryopathy. The candidate proteins include osteocalcin, the matrix GLA protein (MGP) and the enzyme ARSE. Osteocalcin, also called bone Gla protein, and the MGP are two extracellular matrix proteins that contain glutamyl groups, which are posttranslationally modified by a vitamin K-dependent gamma glutamate carboxylase into gamma carboxyglutamic acid residues. The gamma carboxyglutamic acid residues promote the binding of calcium and phosphate ions; this shows that these extracellular matrix proteins are essential for calcium control..$^{35}$

Although some reports suggested that inhibition of carboxylation of osteocalcin is the mechanism proposed for the stippling and the skeletal features seen in warfarin embryopathy, experimental studies found that mice lacking a functional MGP gene are viable, but exhibit increased calcification of growth plate cartilage, short stature, osteopenia and fractures..$^{36-38}$ Furthermore, treatment of rats with warfarin results in excessive mineralization of growth plate cartilage. In humans, mutation in the $M G P$ gene causes Keutel syndrome, a rare autosomal recessive disorder that shares phenotypic similarities with warfarin embryopathy and CDPX.$^{39}$ All these findings were attributed to the anticalcification activities of $M G P .{ }^{40-41}$

The ARSE is a sulfatase enzyme located in the Golgi apparatus; its deficiency causes X-linked CDP. Decrease in the enzymatic activity level was observed with the administration of warfarin. This enzyme could well be a target for the antibodies that cross the placenta to the fetus. ${ }^{42}$

Although autoantibodies may be the largest risk factor for the development of CDP, it might not be the only cause to predict the development of the disease. The very low incidence of the condition in infants of mothers with autoimmune diseases and the recurrence of the condition in a male and female offspring of a mother with $\mathrm{MCTD}^{30}$ point to the possibility of a genetic predisposition. Further studies are required to identify the maternal antibodies associated with CDP and the fetal antigen/pathway disrupted by it.

Thus, CDP should be added to the counseling regarding the fetal potential complications associated with maternal autoimmune diseases. Obstetricians/sonographers taking care of pregnant women with autoimmune conditions should be aware of this complication. The insufficient long-term follow-up data on these children interfere with our ability to provide prognostic information to the couples/mothers during the prenatal counseling.

\section{Conclusion}

CDP is associated with maternal autoimmune diseases, and stippling could be identified on prenatal ultrasound and could identify the affected fetuses. It remains a diagnosis of exclusion until more objective tests are available to confirm the association.

\section{Disclosure}

The authors report no conflicts of interest in this work.

\section{References}

1. Irving MD, Chitty LS, Mansour S, Hall CM. Chondrodysplasia punctata: a clinical diagnostic and radiological review. Clin Dysmorphol. 2008;17(4):229-241.

2. Bravermana NE, Raymondb GV, Rizzoc WB, et al. Peroxisome biogenesis disorders in the Zellweger spectrum: an overview of current diagnosis, clinical manifestations, and treatment guidelines. Mol Genet Metab. 2016;117(3):313-321.

3. Delille HK, Bonekamp NA, Schrader M. Peroxisomes and disease - an overview. Int J Biomed Sci. 2006;2(4):308-314.

4. Porter FD, Herman GE. Malformation syndromes caused by disorders of cholesterol synthesis. J Lipid Res. 2010;52(1):6-34.

5. Rossi M, Hall CM, Bouvier R, et al. Radiographic features of the skeleton in disorders of post-squalene cholesterol biosynthesis. Pediatr Radiol. 2015;45(7):965-976.

6. Morrison SC. Punctate epiphyses associated with Turner syndrome Pediatr Radiol. 1999;29(6):478-480.

7. Perez MJ, Schneider A, Chaze AM, et al. Epiphyseal punctate calcifications (stippling) in complete trisomy 9. Prenat Diagn. 2009;29(11):1085-1088.

8. Sathienkijkanchai A, Wasant P. Fetal warfarin syndrome. J Med Assoc Thail. 2005;88(Suppl 8):S246-S250.

9. Tadros R, Shakib S. Warfarin - indications, risks and drug interactions. Aust Fam Physician. 2010;39(6):476-479.

10. Shearer MJ, Newman P. Metabolism and cell biology of vitamin K. Thromb Haemost. 2008;100(4):530-547.

11. Toriello HV, Erick M, Alessandri JL, et al. Maternal vitamin K deficient embryopathy: association with hyperemesis gravidarum and Crohn disease. Am J Med Genet Part A. 2013;161(3):417-429.

12. Menger H, Lin AE, Toriello HV, Bernert G, Spranger JW. Vitamin K deficiency embryopathy: a phenocopy of the warfarin embryopathy due to a disorder of embryonic vitamin K metabolism. AmJMed Genet. 1997;72(2): $129-134$. 
13. Brunetti-Pierri N, Andreucci MV, Tuzzi R, et al. X-linked recessive chondrodysplasia punctata: spectrum of arylsulfatase $\mathrm{E}$ gene mutations and expanded clinical variability. Am J Med Genet A. 2003;117A(2):164-168.

14. Curry CJR, Micek M, Bertken R, Reichlin M. Chondrodysplasia punctata associated with maternal collagen vascular disease. A new etiology? Presented at the David W. Smith Workshop on Morphogenesis and Malformations, Mont Tremblant, Quebec, August 1993.

15. Costa T, Tiller G, Chitayat D, Silverman E. Maternal systemic lupus erythematosus (SLE) and chondrodysplasia punctata in two infants. Coincidence or association? presented at Bone Dysplasia Society meeting, Chicago, June 1993.

16. Petri M, Orbai A-M, Alarcón GS, et al. Derivationand validation of the systemic lupus international collaborating clinics classification criteria for systemic lupus erythematosus. Arthritis Rheum. 2012;64(8):2677-2686.

17. Lee LA. The clinical spectrum of neonatal lupus. Arch Dermatol Res. 2009;301(1):107-110.

18. McCuistion $\mathrm{CH}$, Schoch EP Jr. Possible discoid lupus erythematosus in newborn infant; report of a case with subsequent development of acute systemic lupus erythematosus in mother. Arch Dermatol Syphilol. 1954;70(6):781-785.

19. Chitayat D, Keating S, Zand DJ, et al. Chondrodysplasia punctata associated with maternal autoimmune diseases: expanding the spectrum from systemic lupus erythematosus (SLE) to mixed connective tissue disease (MCTD) and scleroderma report of eight cases. Am J Med Genet A. 2008;146(23):3038-3053.

20. Mansour S, Liberman D, Young I. Brachytelephalangic chondrodysplasia punctata in an extremely premature infant. Am J Med Genet. 1994;53(1):81-82.

21. Elcioglu N, Hall CM. Maternal systemic lupus erythematosus and chondrodysplasia punctata in two sibs: phenocopy or coincidence? J Med Genet. 1998;35(8):690-694.

22. Austin-Ward E, Castillo S, Cuchacovich M, et al. Neonatal lupus syndrome: a case with chondrodysplasia punctata and other unusual manifestations. J Med Genet. 1998;35(8):695-697.

23. Kelly TE, Alford BA, Greer KM. Chondrodysplasia punctata stemming from maternal lupus erythematosus. Am J Med Genet. 1999;83(5):397-401.

24. Kozlowski K, Basel D, Beighton P. Chondrodysplasia punctata in siblings and maternal lupus erythematosus. Clin Genet. 2004;66(6):545-549.

25. Shanske AL, Bernstein L, Herzog R. Chondrodysplasia punctata and maternal autoimmune disease: a new case and review of the literature. Pediatrics. 2007;120(2):e436-e441.

26. Tim-aroon T, Jaovisidha S, Wattanasirichaigoon D. A new case of maternal lupus-associated chondrodysplasia punctata with extensive spinal anomalies. Am J Med Genet A. 2011;155(6):1487-1491.

27. Roy A, De P, Chakraborty S. Rhizomelic chondrodysplasia punctata with maternal systemic lupus erythromatosus. Indian Pediatr. 2013;50(6):605-607.
28. Sharp GC, Tan EM, Gould RG, Holman HR. Mixed connective tissue disease - an apparently distinct rheumatic disease syndrome associated with a specific antibody to an extractable nuclear antigen (ENA). $\mathrm{Am}$ J Med. 1972;52(2):148-159.

29. Ortega-Hernandez OD, Shoenfeld Y. Mixed connective tissue disease: an overview of clinical manifestations, diagnosis and treatment. Best Pr Res Clin Rheumatol. 2012;26(1):61-72.

30. Schulz SW, Bober M, Johnson C, Braverman N, Jimenez SA. Maternal mixed connective tissue disease and offspring with chondrodysplasia punctata. Semin Arthritis Rheum. 2010;39(5):410-416.

31. Martin V, Lee LA, Askanase AD, Katholi M, Buyon JP. Long-term followup of children with neonatal lupus and their unaffected siblings. Arthritis Rheum. 2002;46(9):2377-2383.

32. Toriello HV. Chondrodysplasia punctata and maternal systemic lupus erythematosus. J Med Genet. 1998;35(8):698-699.

33. Zuppa AA, Riccardi R, Frezza S, Gallini F, et al. Neonatal lupus: followup in infants with anti-SSA/Ro antibodies and review of the literature. Autoimmun Rev. 2017;16(4):427-432.

34. Yamaguchi M, Weitzmann MN. Vitamin K2 stimulates osteoblastogenesis and suppresses osteoclastogenesis by suppressing NF- $\kappa \mathrm{B}$ activation. Int J Mol Med. 2011;27(1):3-14.

35. Yagami K, Suh JY, Enomoto-Iwamoto M, et al. Matrix GLA protein is a developmental regulator of chondrocyte mineralization and, when constitutively expressed, blocks endochondral and intramembranous ossification in the limb. J Cell Biol. 1999;147(5):1097-1108.

36. Lian JB, Gundberg CM. Osteocalcin - biochemical consideration and clinical application. Clin Orthop Relat Res. 1988;(226):267-291.

37. Pauli RM, Lian JB, Mosher DF, Suttie JW. Association of congenital deficiency of multiple vitamin K-dependent coagulation factors and the phenotype of the warfarin embryopathy: clues to the mechanism of teratogenicity of coumarin derivatives. Am J Hum Genet. 1987;41(4):566-583.

38. Luo G, Ducy P, McKee MD, et al. Spontaneous calcification of arteries and cartilage in mice lacking matrix GLA protein. Nature. 1997;6:386(6620):78-81.

39. Weaver KN, El Hallek M, Hopkin RJ, et al. Keutel syndrome: report of two novel MGP mutations and discussion of clinical overlap with arylsulfatase E deficiency and relapsing polychondritis. Am JMed Genet A. 2014;164(4):1062-1068.

40. Oyoung J, Liao Y, Xiao Y, et al. Matrix gla protein inhibits ectopic calcification by a direct interaction with hydroxyapatite crystals. $J \mathrm{Am}$ Chem Soc. 2011;133(45):18406-18412.

41. Schurgers LJ, Spronk HM, Skepper JN, et al. Post-translational modifications regulate matrix Gla protein function: importance for inhibition of vascular smooth muscle cell calcification. J Thromb Haemost. 2007;5(12):2503-2511.

42. Franco B, Meroni G, Parenti G, et al. A cluster of sulfatase genes on Xp22.3: Mutations in chondrodysplasia punctata (CDPX) and implications for warfarin embryopathy. Cell. 1995;81(1):15-25.
The Application of Clinical Genetics

\section{Publish your work in this journal}

The Application of Clinical Genetics is an international, peer-reviewed open access journal that welcomes laboratory and clinical findings in the field of human genetics. Specific topics include: Population genetics; Functional genetics; Natural history of genetic disease; Management of genetic disease; Mechanisms of genetic disease; Counselling and ethical

\section{Dovepress}

issues; Animal models; Pharmacogenetics; Prenatal diagnosis; Dysmorphology. The manuscript management system is completely online and includes a very quick and fair peer-review system, which is all easy to use. Visit http://www.dovepress.com/testimonials.php to read real quotes from published authors. 